\title{
Altered cardiac excitation-contraction coupling in mutant mice with familial hypertrophic cardiomyopathy
}

\author{
Wei Dong Gao, ${ }^{1}$ Nestor Gustavo Pérez, ${ }^{1}$ Christine E. Seidman, ${ }^{2}$ \\ Jonathan G. Seidman, ${ }^{2}$ and Eduardo Marbán ${ }^{1}$ \\ ${ }^{1}$ Section of Molecular and Cellular Cardiology, Department of Medicine, Johns Hopkins University School of Medicine, \\ Baltimore, Maryland 21205, USA \\ ${ }^{2}$ Division of Cardiology, Brigham and Women's Hospital, and Department of Genetics, Harvard Medical School, \\ Boston, Massachusetts 02115, USA \\ Address correspondence to: Eduardo Marbán, Section of Molecular and Cellular Cardiology, Johns Hopkins University \\ School of Medicine, Room 844, Ross Building, 720 Rutland Avenue, Baltimore, Maryland 21205, USA. \\ Phone: (410) 955-2776; Fax: (410) 955-7953; E-mail: marban@jhmi.edu \\ Received for publication September 14, 1998, and accepted in revised form January 18, 1999.
}

\begin{abstract}
Excitation-contraction coupling in cardiac muscle of familial hypertrophic cardiomyopathy (FHC) remains poorly understood, despite the fact that the genetic alterations are well defined. We characterized calcium cycling and contractile activation in trabeculae from a mutant mouse model of FHC (Arg403Gln knockin, $\alpha$-myosin heavy chain). Wild-type mice of the same strain and age ( 20 weeks old) served as controls. During twitch contractions, peak intracellular $\mathrm{Ca}^{2+}\left(\left[\mathrm{Ca}^{2+}\right]_{\mathrm{i}}\right)$ was higher in mutant muscles than in the wild-type $(P<0.05)$, but force development was equivalent in the two groups. $\mathrm{Ca}^{2+}$ transient amplitude increased dramatically in both groups as stimulation rate increased from 0.2 to $4 \mathrm{~Hz}$. Nevertheless, developed force fell at the higher stimulation rates in the mutants but not in controls $(P<0.05)$. The steadystate force- $\left[\mathrm{Ca}^{2+}\right]_{\mathrm{i}}$ relationship was less steep in mutants (Hill coefficient, $2.94 \pm 0.27$ vs. $5.28 \pm 0.64 ; P>$ $0.003)$, with no changes in the $\left[\mathrm{Ca}^{2+}\right]_{\mathrm{i}}$ required for $50 \%$ activation or maximal $\mathrm{Ca}^{2+}$-activated force. Thus, calcium cycling and myofilament properties are both altered in FHC mutant mice: more $\mathrm{Ca}^{2+}$ is mobilized to generate force, but this does not suffice to maintain contractility at high stimulation rates.
\end{abstract}

J. Clin. Invest. 103:661-666 (1999)

\section{Introduction}

Familial hypertrophic cardiomyopathy (FHC) is an inherited autosomal dominant disease characterized by ventricular hypertrophy and myofibrillar disarray. Sudden cardiac death, especially among young athletes, represents the most severe outcome of FHC in affected individuals (1-3). The genetic alterations have been localized to genes that encode various myofibrillar proteins $(4,5)$. Among these, the $\beta$-myosin heavy chain ( $\beta$-MHC) gene was the first to be implicated and remains the most common identified cause of FHC. Recently, a transgenic model of FHC in mice with truncated troponin $\mathrm{T}$ (TnT) has also been developed (6). These transgenic mice hearts are smaller than wild-type, with fewer myocytes, but they exhibit significant delay in relaxation in response to increased work load with mild systolic dysfunction. Despite these advances, it is not yet clear how the genetic lesions produce the characteristic phenotype.

Few studies have attempted to investigate the functional abnormalities of hypertrophic cardiac muscles of FHC. Lin et al. (7) showed increased motility of thin filaments containing mutant $\operatorname{Tn} \mathrm{T}(\operatorname{Tn} \mathrm{T} \mathrm{I91N)}$, a lesion associated with FHC. Similarly, myotubes with truncated TnT (also implicated in FHC) produced less force (8). Mutated myosin molecules also demonstrated decreased actin translocating activity (9). Nevertheless, direct evidence of altered function in intact myocardium is sparse, and little is known about the pathophysiology of excitation-contraction coupling in FHC.
The recent introduction of an FHC mutation (Arg403Gln) into the mouse $\alpha-M H C$ gene has produced an animal model resembling, in many aspects, human FHC (10). Here, we have studied the physiological properties of muscles from the hearts of these mice. The results indicate that there are alterations in excitation-contraction coupling in mutant mice, with lesions in myofilament contraction and associated changes of intracellular $\mathrm{Ca}^{2+}\left(\left[\mathrm{Ca}^{2+}\right]_{i}\right)$ handling.

\section{Methods}

Mouse muscle preparation. Adult male mice (Black Swiss strain, $\sim 20$ weeks old, $\sim 35 \mathrm{~g}$; for a detailed description of the mouse model of FHC, see ref. 10) were anesthetized by intra-abdominal injection of sodium pentobarbital ( 10-20 mg), and the hearts were rapidly excised via midsternal thoracotomy. As described for wild-type mice of another strain (11), the hearts were retrogradely perfused with modified Krebs-Henseleit $(\mathrm{KH})$ buffer with high $\mathrm{K}^{+}(20 \mathrm{mM})$ and gassed with a $95 \% \mathrm{O}_{2} / 5 \% \mathrm{CO}_{2}$ gas mixture in a dissection dish at room temperature. Trabeculae or small papillary muscles (in $\mathrm{mm}$ : wild-type $0.90 \pm 0.34$ long, $0.18 \pm 0.08$ wide, and $0.11 \pm 0.05$ thick, $n=8$; mutant $0.70 \pm 0.21$ long, $0.21 \pm 0.10$ wide, and $0.12 \pm$ 0.04 thick, $n=8$; mean $\pm \mathrm{SD}$ ) were quickly dissected from the right ventricle and mounted between a force transducer and a micromanipulator in a perfusion bath. The muscles were superfused with $\mathrm{KH}$ buffer equilibrated with $95 \% \mathrm{O}_{2} / 5 \% \mathrm{CO}_{2}$. The $\mathrm{KH}$ buffer was composed of (in $\mathrm{mM}$ ): $142 \mathrm{Na}^{+}, 5 \mathrm{~K}^{+}, 1.2 \mathrm{Mg}^{2+}, 127.4 \mathrm{Cl}^{-}, 2$ $\mathrm{PO}_{4^{-}}, 20 \mathrm{HCO}_{3}^{-}, 1.0 \mathrm{CaCl}_{2}$ (pH 7.35-7.4). The perfusion rate was $\sim 10 \mathrm{ml} / \mathrm{min}$, and the preparations were stimulated at $0.5 \mathrm{~Hz}$ unless otherwise indicated. All experiments were performed at 

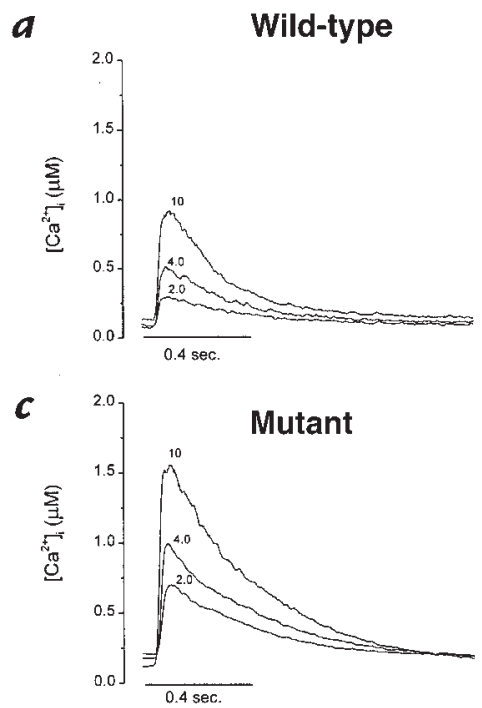

$b$

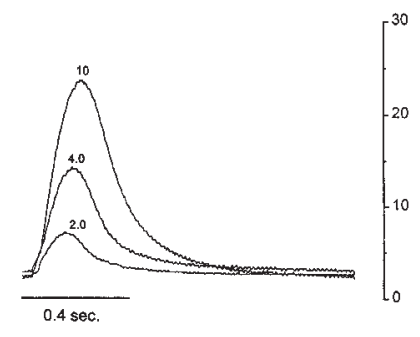

$d$

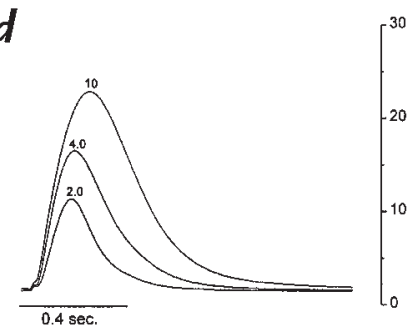

Figure 1

Changes of $\mathrm{Ca}^{2+}$ transients ( $\boldsymbol{a}$ and $\boldsymbol{c}$ ) and twitch force ( $\boldsymbol{b}$ and $\boldsymbol{d}$ ) in a representative mouse ventricular trabecula at 2.0, 4.0, and $8.0 \mathrm{mM}\left[\mathrm{Ca}^{2+}\right]_{\mathrm{o}}$. The muscle was superfused with modified $\mathrm{KH}$ buffer and stimulated at $0.5 \mathrm{~Hz}$. Increases in $\left[\mathrm{Ca}^{2+}\right]_{\mathrm{o}}$ from 2.0 to 8.0 $\mathrm{mM}$ increased systolic $\left[\mathrm{Ca}^{2+}\right]_{\text {i from }} 0.61$ to $1.51 \mathrm{mM}$, and twitch force from 9.8 to $42 \mathrm{mN} / \mathrm{mm}^{2}$. There were no significant changes in diastolic $\left[\mathrm{Ca}^{2+}\right]_{i}$ or force. $\left[\mathrm{Ca}^{2+}\right]_{i}$, intracellular $\mathrm{Ca}^{2+}$ concentration; $\left[\mathrm{Ca}^{2+}\right]_{o}$, extracellular $\mathrm{Ca}^{2+}$ concentration; $\mathrm{KH}$, KrebsHenseleit. room temperature $\left(20-22^{\circ} \mathrm{C}\right)$. Force and sarcomere length were measured as described previously (12). Diastolic sacromere length (SL) was measured by laser diffraction, set to $2.1-2.2 \mathrm{~mm}$, and monitored throughout the experiments. The preparations were field stimulated with 5-ms pulses (Grass S44 Stimulator; Grass Instruments Co., Quincy, Massachusetts, USA). Tetanization was achieved by stimulating the preparations at $10 \mathrm{~Hz}$ in the presence of cyclopiazonic acid $(50 \mathrm{mM})$ at varied extracellular $\mathrm{Ca}^{2+}\left(\left[\mathrm{Ca}^{2+}\right]_{\mathrm{o}}\right)$ (usually $0.5-15 \mathrm{mM}$ ).

Measurement of $\left[\mathrm{Ca}^{2+}\right]_{i}$ with fura-2. For the experiments to be technically successful, muscles must be long, thin, and nonbranching; such muscles are found only in $~ 25 \%$ of mouse hearts (11). $\left[\mathrm{Ca}^{2+}\right]_{\mathrm{i}}$ was measured with fura- 2 potassium salt introduced iontophoretically into one cell and allowed to spread throughout the muscle via gap junctions as described previously (12). Approximately $75 \%$ of microinjected muscles survived the loading protocol and remained stable in terms of force development and sarcomere pattern throughout the experimental protocol. Primarily because of the infrequency of geometrically suitable preparations, the overall success rate of getting a working muscle preparation was $\sim 15 \%$ (11). There was no difference in stability of the muscles or success rate between the two groups.

$\left[\mathrm{Ca}^{2+}\right]_{i}$ was determined by measuring the epifluorescence of fura- 2 in the cells excited using ultraviolet light at $380 \mathrm{~nm}$ and $340 \mathrm{~nm}$. The fluorescent light was collected at $510 \mathrm{~nm}$ by a photomultiplier tube (R1527; Hamamatsu Instruments Co., Bridgeport, New Jersey, USA). The output of the photomultiplier tube was filtered at $100 \mathrm{~Hz}$, collected by an A/D converter, and stored in the computer for later analysis.

$\left[\mathrm{Ca}^{2+}\right]_{i}$ was given by the following equation (after subtraction of the autofluorescence of the muscle): $\left[\mathrm{Ca}^{2+}\right]_{\mathrm{i}}=K_{\mathrm{d}}^{\prime}\left(\mathrm{R}-\mathrm{R}_{\min }\right) /$ $\left(\mathrm{R}_{\max }-\mathrm{R}\right)$, where $\mathrm{R}$ is the observed ratio of fluorescence (340 $\mathrm{nm} / 380 \mathrm{~nm}), K_{\mathrm{d}}^{\prime}$ is the apparent dissociation constant, $R_{\max }$ is the ratio of $340 \mathrm{~nm} / 380 \mathrm{~nm}$ at saturating $\left[\mathrm{Ca}^{2+}\right]$, and $R_{\min }$ is the ratio of $340 \mathrm{~nm} / 380 \mathrm{~nm}$ at zero $\left[\mathrm{Ca}^{2+}\right]$. The values for $\mathrm{K}_{\mathrm{d}}^{\prime}, \mathrm{R}_{\max }$, and $\mathrm{R}_{\min }$ were taken from our previous study in mouse (11).

Statistics. Student's $t$ test and ANOVA were used for statistical analysis of the data $(13,14)$. A value of $P<0.05$ was considered to indicate significant differences between groups. Unless otherwise indicated, pooled data are expressed as mean \pm SEM.

\section{Results}

Effect of $\left[\mathrm{Ca}^{2+}\right]_{0}$ on twitch force. We first characterized force development and calcium cycling during twitch contractions. Figure 1 compares calcium transients ( $a$ and $c)$ and force $(b$ and $d)$ in representative wild-type ( $a$ and $b)$ and mutant $(c$ and $d)$ muscles, at various $\left[\mathrm{Ca}^{2+}\right]_{\mathrm{o}}$. In both groups, calcium transient amplitude and force increase as $\left[\mathrm{Ca}^{2+}\right]_{\mathrm{o}}$ is elevated from 2 to 4 to $10 \mathrm{mM}$. Note, however, that $\mathrm{Ca}^{2+}$ transient amplitudes are distinctly greater in the mutant muscle than in wild-type, despite the fact that systolic and diastolic forces were roughly equal at each $\left[\mathrm{Ca}^{2+}\right]_{0}$.

The pooled data in Fig. 2 confirm that the discrepancy between calcium cycling and force was consistent and significant. At any given $\left[\mathrm{Ca}^{2+}\right]_{\mathrm{o}}$, more intracellular $\mathrm{Ca}^{2+}$ is required in the mutant muscles to generate the same levels of force. As another way of gauging the relationship between $\left[\mathrm{Ca}^{2+}\right]_{\mathrm{i}}$ and force during twitch contractions, we plotted peak $\left[\mathrm{Ca}^{2+}\right]_{\mathrm{i}}$ against peak force in each muscle (Fig. 3). Although there is no difference in the slopes $(P=0.2)$, the relationship from the mutant muscles is shifted to the right relative to the wild-type. Note also that the mutant muscles reach higher values of $\left[\mathrm{Ca}^{2+}\right]_{\mathrm{i}}$ during the generation of equivalent forces. These data clearly show that excitation-contraction coupling is abnormal in mutant myocardium. Moreover, the changes are distinctive, differing from those described previously in stunned myocardium (15).

Dynamics of twitches and $\mathrm{Ca}^{2+}$ transients in wild-type and mutant muscles at varied $\left[\mathrm{Ca}^{2+}\right]_{0}$. We next looked for possible alterations in the time course of calcium and force during twitch contractions. Figure 4 plots the times to peak $(a$ and $b)$ and half-relaxation ( $c$ and $d$ ) for twitch force $\left(a\right.$ and $c$ ) and $\mathrm{Ca}^{2+}$ transients $(b$ and $d)$. The times to peak force increased equivalently as $\left[\mathrm{Ca}^{2+}\right]_{0}$ was raised in the two groups, whereas the times to peak $\left[\mathrm{Ca}^{2+}\right]_{\mathrm{i}}$ were not affected by changes in $\left[\mathrm{Ca}^{2+}\right]_{0}$ in either the wild-type or mutant muscles. The only significant kinetic difference between the two groups was a delay of relaxation of force in the mutant muscles, evident at $\left[\mathrm{Ca}^{2+}\right]_{0}>5 \mathrm{mM}$. Similar delays in relaxation have recently been reported in intact hearts from the same colony of mutant mice (16).

Effect of stimulation frequency on $\left[\mathrm{Ca}^{2+}\right]_{i}$ and force development. Mouse hearts normally contract at very high frequencies $\left(>500 / \mathrm{min}\right.$ at $\left.37^{\circ} \mathrm{C}\right)$, whereas our baseline studies were performed at $0.5 \mathrm{~Hz}\left(20-22^{\circ} \mathrm{C}\right)$. To look for 


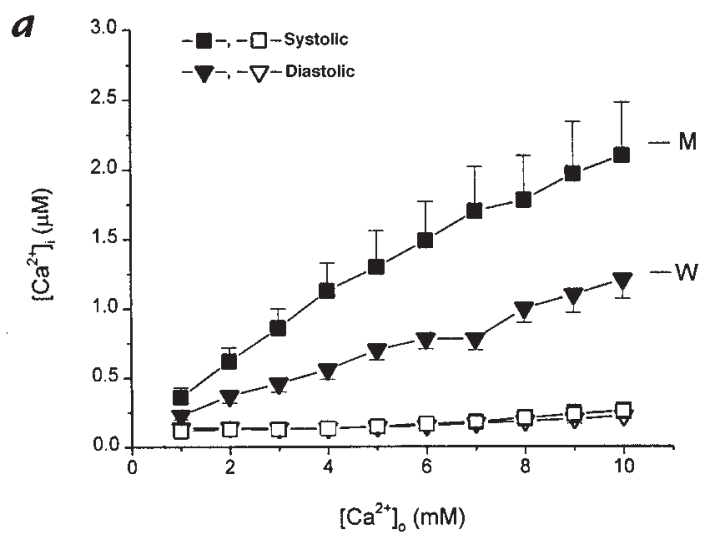

$b$

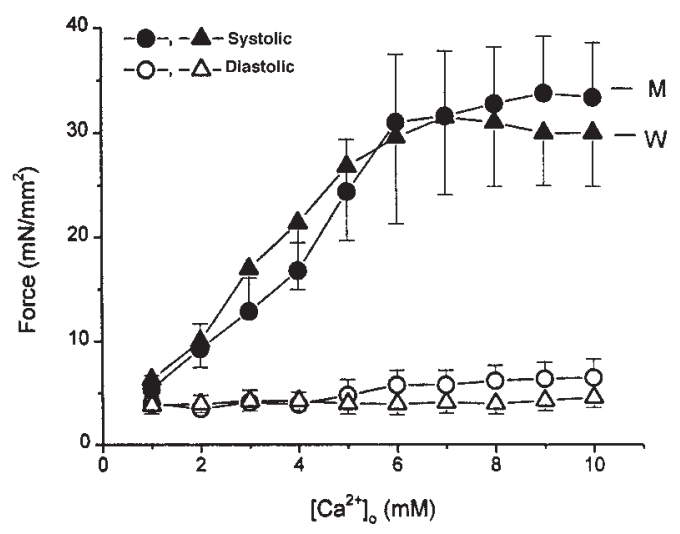

Figure 2

Pooled data of diastolic (open symbols) and systolic (closed symbols) $\left[\mathrm{Ca}^{2+}\right]_{\mathrm{i}}$ (a) and twitch force $(\boldsymbol{b})$ in wild-type $(n=6)$ and mutant muscles $(n=6-7)$ at varied $\left[\mathrm{Ca}^{2+}\right]_{\mathrm{o}}$. Both systolic $\left[\mathrm{Ca}^{2+}\right]_{\mathrm{i}}$ and force increased at higher $\left[\mathrm{Ca}^{2+}\right]_{0}$, with no changes in diastolic $\left[\mathrm{Ca}^{2+}\right]_{i}$ and force in both groups. However, the systolic $\left[\mathrm{Ca}^{2+}\right]_{i}$ is significantly higher in mutant muscles at $\left[\mathrm{Ca}^{2+}\right]_{0}>3.0 \mathrm{mM}(P<0.03)$, with no changes in twitch force between the two groups. All muscles were stimulated at $0.5 \mathrm{~Hz}$ at room temperature. Data are means \pm SEM of at least six muscles from six individual animals.

possible derangements in excitation-contraction coupling at higher frequencies, we increased the stimulation rate in a subset of the muscles to values as high as $4 \mathrm{~Hz}$. As rate increased, $\left[\mathrm{Ca}^{2+}\right]_{\mathrm{i}}$ and force increased in both groups (Fig. $5, a$ and $b$ ). Note, however, that the monotonic increase of force in the wild-type muscles contrasts with a secondary sag of force development at high frequencies in the mutants (Fig. 5b). The mutants also exhibited a greater increase in diastolic force, despite the fact that no such differences were evident in diastolic $\left[\mathrm{Ca}^{2+}\right]_{\mathrm{i}}($ Fig. $5 a$ ). The differences are more obvious in Fig. 5, $c$ and $d$ which plot the increment of $\left[\mathrm{Ca}^{2+}\right]_{i}$ and developed force against stimulation frequency. It is clear that changes in $\left[\mathrm{Ca}^{2+}\right]_{i}$ are qualitatively similar in the two groups (consistent with the data in Fig. 2, there is a tendency for calcium transients to be larger at low frequencies in the mutants); in contrast, developed force diverged in the two groups at the higher stimulation rates, decreasing at frequencies $>2 \mathrm{~Hz}$ in the mutants, but not in wild-type. Thus, contraction is impaired in mutant mice at higher stimulation rates.

Changes in steady-state force- $\left[\mathrm{Ca}^{2+}\right]_{i}$ relationship. The changes in excitation-contraction coupling during twitch contractions include contributions from altered calcium cycling, but the relative importance and nature of myofilament involvement remain unclear. To evaluate myofilament $\mathrm{Ca}^{2+}$ responsiveness directly, steady-state activation (Fig. 6a) was achieved by bursts of rapid pacing in the presence of cyclopiazonic acid $(50 \mathrm{mM})$, a reversible inhibitor of calcium uptake by the sarcoplasmic reticulum. Figure $6 b$ shows the pooled steady-state force- $\left[\mathrm{Ca}^{2+}\right]_{\text {i }}$ relationships in the two groups. Several features of the activation curves are noteworthy. First, maximal $\mathrm{Ca}^{2+}$-activated force, or $\mathrm{F}_{\max }(48 \pm 4.2$ $\mathrm{mN} / \mathrm{mm}^{2}$ in wild-type, $45 \pm 5.5 \mathrm{mN} / \mathrm{mm}^{2}$ in mutant) is lower in both groups compared with muscles from younger mice of another strain (11). An overall comparison of the curves from mutant and wild-type mice reveals significant differences ( $P=0.03$ by multivariate ANOVA). The midpoint of activation is similar in the mutant $\left(\mathrm{Ca}_{50}=1.35 \pm\right.$ $0.17 \mathrm{mM})$ and wild-type muscles $(1.20 \pm 0.07 \mathrm{mM} ; P>0.05)$, but the slopes of the steady-state relationships are shallower in the mutants $(5.30 \pm 0.64$ in wild-type vs. $2.94 \pm 0.27$ in mutant; $P<0.003$ ). As a consequence of the decrease in slope without a change in the midpoint, force in the mutants tends to be greater at lower $\left[\mathrm{Ca}^{2+}\right]_{i}$, but the converse is true at higher $\left[\mathrm{Ca}^{2+}\right]_{i}$. In other words, at low $\left[\mathrm{Ca}^{2+}\right]_{i}$, mutant myofilaments are more sensitive to $\mathrm{Ca}^{2+}$, whereas at higher $\left[\mathrm{Ca}^{2+}\right]$, less force is produced until the two curves converge at $\mathrm{F}_{\max }$. Similar behavior has been observed in skinned mutant muscles from this mouse model (17).

\section{Discussion}

This is the first study of intact cardiac muscle in a mouse model of FHC. Our success in adapting the trabecular force/calcium measurement methodology for use in mouse cardiac muscle (11) enabled us to perform such a study. We have found that there are indeed alterations in the properties of the myofilaments in FHC mutant mice. As will be discussed later in this article, these changes have important implications for the pathophysiology of FHC.

Contraction and $\mathrm{Ca}^{2+}$ transients in mutant muscles. One striking observation from this study was the increased $\mathrm{Ca}^{2+}$ transient amplitude in mutant mice at higher $(>3.0$

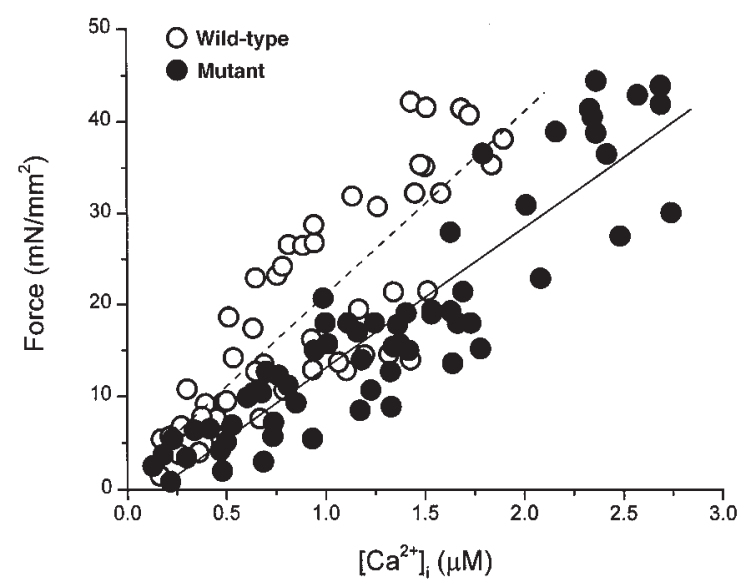

Figure 3

Pooled data of peak force and peak systolic $\left[\mathrm{Ca}^{2+}{ }^{2}\right.$ i from wild-type (closed circles) and mutant (open circles) muscles. Varied levels of force were obtained at different $\left[\mathrm{Ca}^{2+}\right]_{\mathrm{o}}(1.0-10.0 \mathrm{mM})$. Note the different populations of data points between the two groups, with similar slopes when fitted by a linear function. The mean slopes of the two groups were not different: $18 \pm 3\left[\mathrm{Ca}^{2+}\right]_{\mathrm{i}}$ in wild-type vs. $14 \pm 2\left[\mathrm{Ca}^{2+}\right]_{\mathrm{i}}$ in mutant; $P=0.2$. 


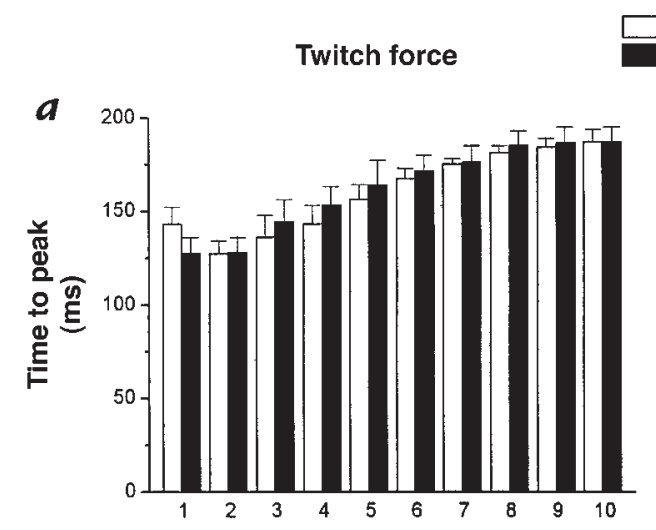

$\mathrm{Ca}^{2+}$ transients

Mutant
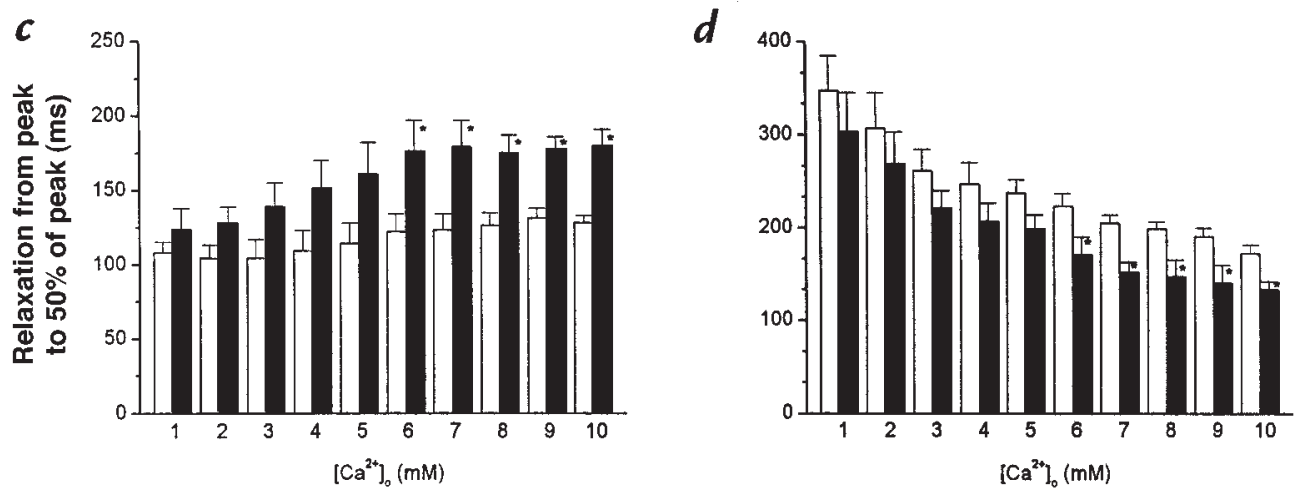

Figure 4

Effects of $\left[\mathrm{Ca}^{2+}\right]_{0}$ on dynamics of force $(\boldsymbol{a}$ and $\boldsymbol{c})$ and $\mathrm{Ca}^{2+}$ transients $(\boldsymbol{b}$ and $\boldsymbol{d})$. Pooled data for time to peak $(\boldsymbol{a}$ and $\boldsymbol{b})$ and time from peak to $50 \%$ relaxation ( $\boldsymbol{c}$ and $\boldsymbol{d})$ of $\mathrm{Ca}^{2+}$ transients and twitch force $\left(n=6 \text { in each group). In both groups, time to peak force increased as [Ca }{ }^{2+}\right]_{0}$ was increased without changes in time to peak $\mathrm{Ca}^{2+}$ transients. In mutant muscles, relaxation of force was significantly prolonged at $\left[\mathrm{Ca}^{2+}\right]_{0}>6.0 \mathrm{mM}$, whereas decay of $\mathrm{Ca}^{2+}$ transients was significantly accelerated. ${ }^{*} P<0.05$.
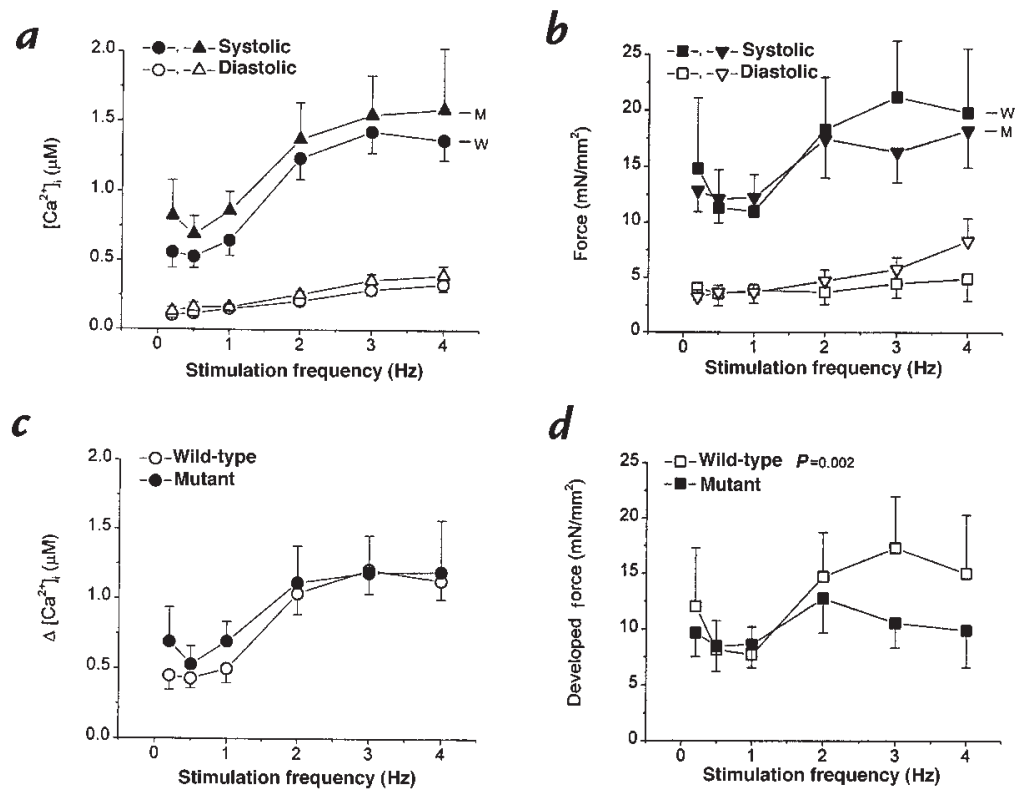

Figure 5

Force-frequency relationship of mouse cardiac muscle. Pooled data of $\left[\mathrm{Ca}^{2+}\right]_{i}(\boldsymbol{a}$ and $\boldsymbol{c})$ and twitch force ( $\boldsymbol{b}$ and $\left.\boldsymbol{d}\right)$ from wild-type (circles and squares; $n=6)$ and mutant (triangles; $n=7)$ muscles are plotted at varied stimulation frequencies at $\left[\mathrm{Ca}^{2+}\right]_{\mathrm{o}}=2.0 \mathrm{mM}$. $(a$ and $b)$ Systolic and diastolic $\left[\mathrm{Ca}^{2+}\right]_{\mathrm{i}}$ and force. Note the increases in both twitch force and $\left[\mathrm{Ca}^{2+}\right]_{i}$ in wild-type muscles when stimulation frequency increased. In mutant muscles, increases in force was blunted at higher stimulation rate, with elevation of diastolic force. $(c$ and $d)$ Changes of $\left[\mathrm{Ca}^{2+}\right]_{i}$ and developed force as stimulation rate was increased. Note the decrease in developed force in mutant muscles at higher stimulation rates. The two response curves are statistically different $(P<0.002)$ by multivariate ANOVA. 


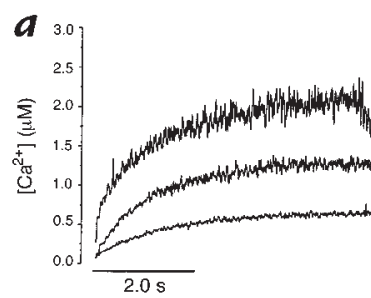

Wild-type
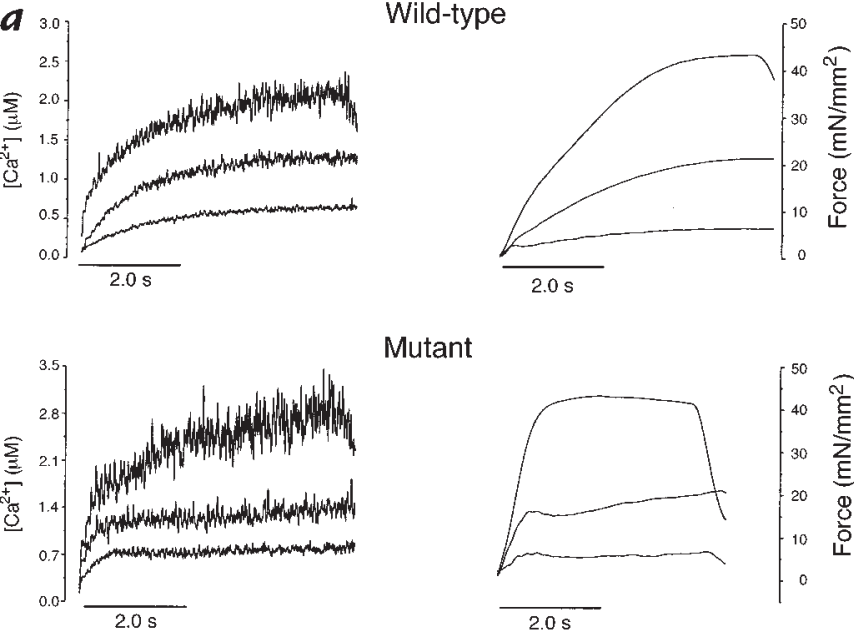

Mutant

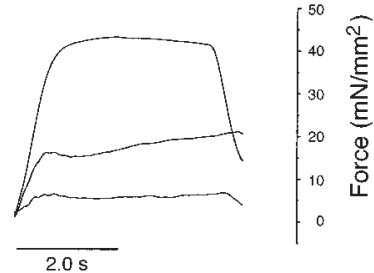

$b$

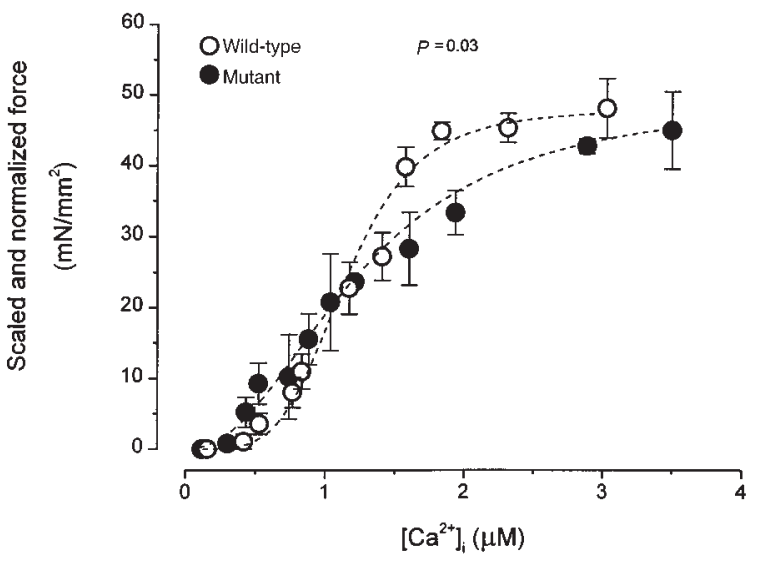

Figure 6

Steady-state force- $\left[\mathrm{Ca}^{2+}\right]_{i}$ relationship of mouse cardiac muscle. $(\boldsymbol{a})$ Recordings of $\left[\mathrm{Ca}^{2+}\right]_{\mathrm{i}}($ left $)$ and force (right) at different levels of activation from one muscle in each group. Tetanizations were achieved by stimulating the muscle at $10 \mathrm{~Hz}$ in the presence of cyclopiazonic acid (50 mM) at varied $\left[\mathrm{Ca}^{2+}\right]_{0}$ to obtain different levels of tetanization. (b) Pooled data for steady-state force- $\left[\mathrm{Ca}^{2+}\right]$ relationships of wild-type $($ open circles; $n=5)$ and mutant (closed circles; $n=8)$ muscles. Data were grouped in various bins of $\left[\mathrm{Ca}^{2+}\right]_{\mathrm{i}}$. The absolute $\mathrm{F}_{\max }$ are shown as means $\pm \mathrm{SEM}$ and are plotted at highest $\left[\mathrm{Ca}^{2+}\right]_{i}$. All other force levels were normalized with respect to their own maximal values. The dashed lines are the Hill fits, based on the means of Ca 50 and Hill coefficient in each group. In mutant muscles, there is a less-steep force-[Ca $\left.{ }^{2+}\right]$ i relationship, which also crosses over that of the wild-type at $\sim \mathrm{Ca}_{50} . P<0.03$ by multivariate ANOVA. $\mathrm{Ca}_{50},\left[\mathrm{Ca}^{2+}\right]_{\mathrm{i}}$ required for $50 \%$ of maximal activation; $F_{\text {max }}$, maximal $\mathrm{Ca}^{2+}$-activated force.

$\mathrm{mM})\left[\mathrm{Ca}^{2+}\right]_{\mathrm{o}}$, despite the fact that twitch force remained the same as in wild-type (Fig. 2). This may intuitively lead one to believe that $\mathrm{Ca}^{2+}$ responsiveness of mutant muscle is decreased, because more $\left[\mathrm{Ca}^{2+}\right]_{i}$ was required to produce equivalent levels of force, as in stunned myocardium (15). Nevertheless, several features of mutant muscles distinguish them phenotypically from stunned myocardium. First, FHC muscle exhibits the adaptive response of an increase in $\left[\mathrm{Ca}^{2+}\right]_{i}$ to maintain force; i.e., more $\mathrm{Ca}^{2+}$ is more mobilized. This may be due either to increased entry of $\mathrm{Ca}^{2+}$ or increased release of $\mathrm{Ca}^{2+}$ from the sarcoplasmic reticulum, or both. Second, the specific features of the decrease in $\mathrm{Ca}^{2+}$ responsiveness in FHC mice are unique: when peak force and peak $\left[\mathrm{Ca}^{2+}\right]_{\text {i }}$ were plotted against each other (Fig. 3), there was no significant difference between the slopes of the relationships, but rather a parallel rightward shift of the relationship in mutant muscles. Obviously, a different mechanism than the one responsible for stunning is responsible for the decreased $\mathrm{Ca}^{2+}$ responsiveness observed here. Primary alterations of cross-bridge cycling kinetics can be manifested as changes in steady-state myofilament $\mathrm{Ca}^{2+}$ responsiveness (18); further studies will be required to ascertain the mechanism of these changes and their relationship to specific steps in cross-bridge cycling.

Changes in relaxation of mutant muscles. In both groups of muscles, relaxation became slower as $\left[\mathrm{Ca}^{2+}\right]_{0}$ was raised (Fig. 4). This slowing of relaxation was apparently unrelated to $\left[\mathrm{Ca}^{2+}\right]_{\mathrm{i}}$, because the decay of $\mathrm{Ca}^{2+}$ transients was, paradoxically, accelerated. As discussed previously (11), the delay of relaxation of force in the face of accelerated relaxation of $\mathrm{Ca}^{2+}$ transients is likely the result of force-dependent changes in the affinity of the myofilaments to $\mathrm{Ca}^{2+}$ at higher levels of force (19). However, if an increase in the myofilament affinity for $\mathrm{Ca}^{2+}$ were the sole mechanism, one would also expect higher peak force in mutant muscle, which was not observed. Increases in $\left[\mathrm{Ca}^{2+}\right]_{i}$ have multiple effects that feed back upon relaxation. Phosphorylation of troponin I by $\mathrm{Ca} /$ calmodulin-dependent protein kinase II (CaMKII) decreases force development and accelerates relaxation (20); the kinase also increases $\mathrm{Ca}^{2+}$ reuptake by the sarcoplasmic reticulum (21). Although the idea is reasonable and merits further study, the possible involvement of protein kinase systems in the abnormal relaxation of mutant myocardium remains conjectural.

Effect of stimulation frequency in mutant muscles. Normal mouse cardiac muscle was found to have a positive force-frequency relationship (11), and this feature was also observed in the wild-type muscles studied here (Fig. $5 b$ ). The frequency-dependent potentiation of force was less pronounced in the present study, possibly owing to the use of older animals and/or to genuine differences between inbred mouse strains. In mutant muscles, diastolic force increased with stimulation frequency without concomitant changes of $\left[\mathrm{Ca}^{2+}\right]_{\mathrm{i}}$. The increased diastolic force may simply reflect the previously discussed impairment of relaxation when $\mathrm{Ca}^{2+}$ is high (Fig. 4). On the other hand, the failure to produce higher systolic force presumably reflects a defect of force-generating ability of the mutant myofilaments, because $\mathrm{Ca}^{2+}$ transients did not change. The negative force-frequency relationship provides a specific rationale for heart failure, especially during exercise. The delayed relaxation may underlie the diastolic dysfunction of FHC as well.

Steady-state force- $\left[\mathrm{Ca}^{2+}\right]_{i}$ relationship in mutant muscles. The steady-state force- $\left[\mathrm{Ca}^{2+}\right]_{i}$ relationship in FHC myocardium is clearly different from that of wild-type (Fig. 6b). This difference is mainly caused by a decrease in the cooperativity of the myofilaments. Because nor- 
mal mouse muscle has high myofilament cooperativity (Fig. $6 b$ and ref. 11), the decrease is expected to have a retarding effect on force development, especially when $\left[\mathrm{Ca}^{2+}\right]_{\mathrm{i}}$ is submaximal. Another alteration in the relationship worth noting is the cross-over with that of wild-type at $\sim \mathrm{Ca}_{50}$. As already discussed, this feature may be manifested as changes in relaxation dynamics (Fig. 4). The mechanism for decreased cooperativity in mutant muscle is not understood at present, but it would not be surprising if it turns out to be a direct consequence of the structural alteration (Arg403Gln) in the myosin heavy chain.

While our findings reveal novel alterations of calcium cycling in FHC mutant muscle, the underlying mechanisms remain to be explored. Given the nature of the primary defect, these alterations may well be secondary to altered mechanics due to defective myofilament structure. We can clearly conclude that, for whatever reason, $\mathrm{Ca}^{2+}$ mobilization is upregulated in FHC myocardium. These changes in $\mathrm{Ca}^{2+}$ regulation may have numerous potential sequelae yet to be characterized. Given what we know about the key role of $\left[\mathrm{Ca}^{2+}\right]_{\mathrm{i}}$ in the pathogenesis of cardiac arrhythmias (22), it seems probable that the higher incidence of sudden cardiac death in FHC with Arg403Gln mutation arises from the alterations in calcium cycling, rather than directly from the myofilament defect. In this respect, it would be very interesting to investigate whether changes in calcium cycling are less marked in muscles containing more benign mutations in myosin, e.g., Val606Met.

\section{Acknowledgments}

Supported by National Institutes of Health grant R01 HL44065 (to E. Marbán).

1. Maron, B.J., Epstein, S.E., and Roberts, W.C. 1986. Causes of sudden death in young athletes. J. Am. Coll. Cardiol. 7:204-214.

2. Codd, M.B., Sugrue, D.D., and Gersh, B.J. 1989. Epidemiology of idiopathic dilated and hypertrophic cardiomyopathy. Circulation. 67:1227.

3. Marian, A. 1995. Sudden cardiac death in patients with hypertrophic cardiomyopathy: from bench to bedside with an emphasis on genetic markers. Clin. Cardiol. 18:189-198.

4. Marian, A.J., and Roberts, R. 1995. Recent advances in the molecular genetics of hypertrophic cardiomyopathy. Circulation. 92:1336-1347.

5. Seidman, C.E., and Seidman, J.G. 1996. Gene mutations that cause familial hypertrophic cardiomyopathy. In Scientific American: molecular cardiovascular medicine. E. Haber, editor. Scientific American. New York, NY. 193-209.

6. Tardiff, J.C., et al. 1998. A truncated cardiac troponin T molecule in transgenic mice suggests multiple cellular mechanisms for familial hypertrophic cardiomyopathy. J. Clin. Invest. 101:2800-2811.

7. Lin, D., Bobkova, A., Homsher, E., and Tobacman, L.S. 1996. Altered cardiac troponin $\mathrm{T}$ in vitro function in the presence of a mutation implicated in familial hypertrophic cardiomyopathy. J. Clin. Invest. 97:2842-2848.

8. Watkins, H., Seidman, C.E., Seidman, J.G., Feng, H.S., and Sweeney, H.L. 1996. Expression and functional assessment of a truncated cardiac troponin $\mathrm{T}$ that causes hypertrophic cardiomyopathy. J. Clin. Invest. 98:2456-2461.

9. Sata, M., and Ikebe, M. 1996. Functional analysis of the mutations in the human cardiac beta-myosin that are responsible for familial hypertrophic cardiomyopathy. J. Clin. Invest. 98:2866-2873.

10. Geisterfer-Lowrance, A., et al. 1996. A mouse model of familial hypertrophic cardiomyopathy. Science. 272:731-734.

11. Gao, W.D., Perez, N.G., and Marbán, E. 1998. Calcium cycling and contractile activation in intact mouse cardiac muscle. J. Physiol. 507:175-184.

12. Gao, W.D., Liu, Y., Mellgren, R., and Marbán, E. 1996. Intrinsic myofilament alterations underlying the decreased contractility of stunned myocardium. A consequence of $\mathrm{Ca}^{+}$-dependent proteolysis? Circ. Res. 78:455-465.

13. Snedecor, G.W., and Cochran, W.G. 1989. Statistical methods. Iowa State University Press. Ames, IA.

14. Winer, B.J. 1989. Statistical principles in experimental design. McGraw-Hill. New York, NY.

15. Gao, W.D., Atar, D., Backx, P.H., and Marbán, E. 1995. Relationship between intracellular calcium and contractile force in stunned myocardium. Direct evidence for decreased myofilament $\mathrm{Ca} 2+$ responsiveness and altered diastolic function in intact ventricular muscle. Circ. Res. 76:1036-1048.

16. Spindler, M., et al. 1998. Diastolic dysfunction and altered energetics in the alpha-MHC(403/+) mouse model of familial hypertrophic cardiomyopathy. J. Clin. Invest. 101:1775-1783.

17. Blanchard, E., et al. 1996. Altered calcium sensitivity of cardiac muscle from a mouse model of Arg403Gln familial hypertrophic cardiomyopathy. Proceedings of the Scientific Conference on the Molecular Biology of the Normal, Hypertrophied, and Failing Heart. Salt Lake City, Utah. 86.

18. Brenner, B. 1998. Changes in calcium sensitivity at the cross-bridge level. In Modulation of cardiac calcium sensitivity. A new approach to increasing the strength of the heart. J.A. Lee and D.G. Allen, editors. Oxford University Press. Oxford, United Kingdom. 197-214.

19. Kurihara, S. 1994. Regulation of cardiac muscle contraction by intracellular Ca2+ [review].Jpn. J. Physiol. 44:591-611.

20. Solaro, J. 1993. Modulation of activation of cardiac myofilaments by beta-adrenergic agonists. In Modulation of cardiac calcium sensitivity. A new approach to increasing the strength of the heart. J.A. Lee and D.G. Allen, editors. Oxford University Press. Oxford, United Kingdom. 160-177.

21. Bassani, R.A., Mattiazzi, A., and Bers, D.M. 1995. CaMKII is responsible for activity-dependent acceleration of relaxation in rat ventricular myocytes. Am. J. Physiol. 268:H703-H712.

22. Márban, E. 1998 Molecular approaches to arrhythmogenesis. In Molecular basis of cardiovascular disease. K.R Chien, editor. W.B. Saunders. Philadelphia, PA. 313-328. 